\title{
Necrotising Pancreatitis- A Cross-sectional Study on Surgical Outcomes of Pancreatic Necrosectomy
}

\section{ABSTRACT}

Introduction: Necrotising Pancreatitis (NP) is the severe form of acute pancreatitis accounting for significant mortality (15$40 \%)$, morbidity ( 25\%) and has significant health costs. The traditional management of infected necrosis has centered on open surgical debridement which is accompanied by significant risk of stress, organ failure and complications. Short-term and long-term functional outcomes after operative treatment of NP have not been studied extensively.

Aim: To evaluate the short-term and long-term surgical outcomes in patients undergoing surgery for NP.

Materials and Methods: This was a cross-sectional study of patients who underwent surgery for NP conducted at Manipal Hospital, Bangalore between June 2009 to March 2016. The electronic records pertaining to such patients were retrieved. Various surgeries done were grouped. Surgical complications and short-term outcomes like new onset organ failure, Surgical Site Infection (SSIs), haemorrhage, bowel fistula, re-explorations, and requirement of additional procedures, hospital stay and the mortality were studied by hospital data. Long-term outcomes like endocrine/exocrine insufficiency, weight loss, recurrent pancreatitis, incision hernia were studied by prospective data collected from telephonic interview; questionnaires in addition to data collected as and when patient gets admitted and in Outpatient Department (OPD) during follow-up. A comparison with different surgical techniques like laparoscopy, open necrosectomy, Video assisted necrosectomy was made. Statistical analyses were performed by STATA 11.2 (College Station TX USA). Mann-Whitney test were used to find the significance difference between the length of stay and Intensive Care Unit (ICU) stay with the groups and it is expressed as mean and standard deviation, Chi-square test has been used to measure the association between different clinical variables. $p<0.05$ was considered as statistically significance.

Results: Forty six patients underwent surgical treatment during the study period. Patients' age ranged from 25 to 75 years (median age44 years). Median postoperative ICU stay was 12 days (range of 01 32 days). The mean follow-up was 3.5 years. The overall mortality rate was $26 \%$ (12 patients). The mortality rates between laparatomy (33\%) and minimally invasive necrosectomy (23\%) groups were not significantly different $(p=0.436)$. Secondary diabetes mellitus was observed in $18(40 \%)$ and exocrine insufficiency in $8(18 \%)$ of patients. The other long-term complications were recurrent pancreatitis in 7 (15\%), biliary stricture $3(6 \%)$ and incisional hernia in $3(6 \%)$.

Conclusion: Mortality rate, organ failure rates and median ICU admission rate were similar across all surgical techniques though there was a trend of overall reduced complication rate. A long-term and close follow-up is advised in these patients for the late complications to be identified and treated.

\section{INTRODUCTION}

The NP has high morbidity and mortality. Approximately, 25\% of patients with acute pancreatitis develop NP associated with organ dysfunction requiring ICU admission [1]. Mortality of NP varies from $15 \%$ in patients with sterile necrosis to as much as $40 \%$ in patients with infected necrosis $[2,3]$.

The initial treatment of acute NP is conservative. Once pancreatic necrosis becomes infected mortality increases steeply. Intervention is indicated when infection of pancreatic necrosis is proven by Fine Needle Aspiration (FNA), when pancreatic air collections in the necrotic cavity are depicted on Computer Tomography (CT) scan [Table/Fig-1] or when sepsis/organ failure persists despite maximal support on the ICU [4-6].

Surgical intervention within the first 14 days after the onset of symptoms should be averted because of disreputably poor outcome in this stage of disease [6,7]. In general, sterile necrosis does not require intervention, while infected necrosis usually requires operative debridement. The management of sterile necrosis with organ dysfunction is controversial [8,9]. The traditional management of infected necrosis has centered on open surgical debridement, with additional percutaneous drainage and peritoneal lavage and all of which requires multiple sessions and interventions. The open

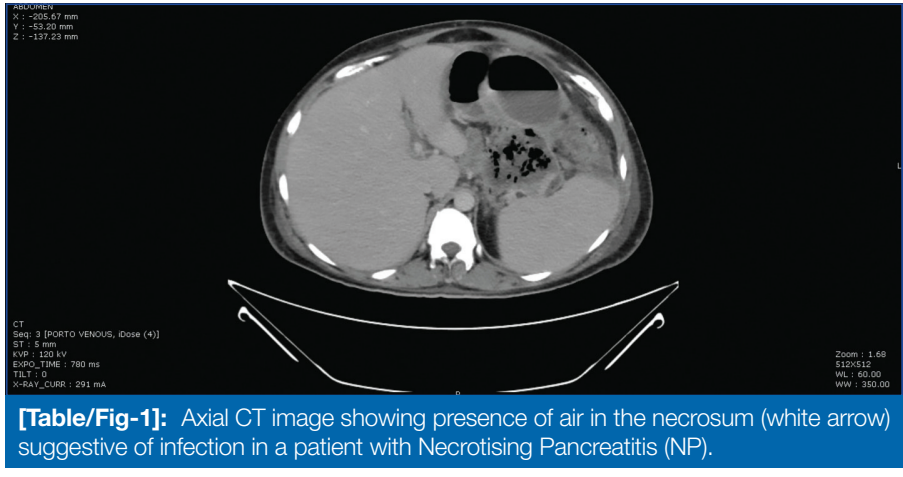

surgical debridement is accompanied by significant risk of stress, organ failure and long-term complications including external fistulas, incisional hernias, endocrine and exocrine insufficiency [8-11].

The landmark study in the management of NP is the PANTER trial which revealed that, reduction in the major morbidity is by a minimally invasive "step-up" approach instead of maximal necrosectomy by laparotomy $[10,11]$. Short-term and long-term functional outcomes after operative treatment of NP have not been studied extensively. This study was undertaken to assess the outcomes of PN at the tertiary referral center. 


\section{MATERIALS AND METHODS}

The cross-sectional study was conducted at Manipal Hospital, Bangalore, Karnataka, India for a period of 18 months from October 2014 to March 2016. Institutional ethical clearance was obtained.

Infected necrotic tissue was defined as the presence of gas in the fluid collection on contrast-enhanced CT. Suspected infected necrosis was defined as persistent sepsis or progressive clinical deterioration despite maximal support in the ICU, without documentation of infected necrosis. [2,3,7-9] Modified CT Severity Index (CTSI) was used to assess the severity of NP [2,3].

The data on the outcomes of necrosectomy in patients who underwent PN from June 2009 to March 2016 were collected, analysed and followed-up.

Inclusion criteria: All the patients who underwent surgery for denovo NP during this period were included in the study.

Exclusion criteria: The exclusion criteria were a flare-up of chronic pancreatitis, previous exploratory laparotomy during the current episode of pancreatitis, pancreatitis caused by abdominal surgery.

\section{Study Procedure}

The retrospective data was collected from the hospital data system, register and questionnaire through phone call. The prospective data was collected as and when patient gets admitted and in OPDs during follow-up.

Different approaches are described for necrosectomy. Traditionally, open necrosectomy is performed. With surgical experience and evolving technology minimally invasive techniques like laparoscopy, Videos Assisted Retroperitoneal Debridement (VARD) was adopted. These groups were compared. In present study, fifteen patients underwent open necrosectomy, of which five patients had transgastric necrosectomy, nine patients underwent via gastrocolic approach and one through mesocolic approach. Minimal Invasive Pancreatic Necrosectomy (MIPN) was performed on 31 patients, of which 17 patients underwent laparoscopic necrosectomy and 14 patients underwent VARD. The short outcomes measured were new onset of single or multiorgan failure, SSls, haemorrhage, bowel fistula, reexplorations, requirements of additional procedures, hospital stay and the mortality. Long-term outcomes were endocrine/exocrine insufficiency, recurrent pancreatitis, incisional hernia.

\section{STATISTICAL ANALYSIS}

The statistical analyses were performed by STATA 11.2 (College Station TX USA). Mann-Whitney test were used to find the significance difference between the length of stay and ICU stay between groups and it is expressed as mean and standard deviation, Chi-square test was used to measure the association between the postoperative organ failure, mortality, additional procedures, SSI, haemorrhage, fistula, readmissions, recurrent pancreatitis and incisional hernia between the groups respectively, and was expressed as frequency and percentage, the above variables also performed descriptive statistics. The $p<0.05$ was considered as statistically significance.

\section{RESULTS}

Total 46 (n) patients who underwent PN were enrolled in the study. Out of 46 patients, 42 (91.3\%) were males and 4 (8.7\%) were females. Median age of patients at presentation was 44 years (Range 25-75 years). Most common aetiology was gallstones. About 19 (41.3\%) of patients had biliary pancreatitis, 13 (28.3\%) were alcohol induced, various other aetiologies are provided in [Table/Fig-2]. In 08 (17.4\%) patients, cause could not be detected and labeled as idiopathic.

\begin{tabular}{|c|c|c|}
\hline Variable & Number (n) & $\%$ or (range) \\
\hline Median age (years) & 44 & $25-75$ \\
\hline Male: female & $42: 4$ & 91.3:8.7 \\
\hline \multicolumn{3}{|l|}{ Aetiology: } \\
\hline Gallstone & 19 & 41.3 \\
\hline Alcohol & 13 & 28.2 \\
\hline Idiopathic & 08 & 17.4 \\
\hline Hypertriglyceridaemia & 03 & 6.5 \\
\hline Hypercalcaemia & 01 & 2.2 \\
\hline Viral & 01 & 2.2 \\
\hline Pancreatic divisum & 01 & 2.2 \\
\hline Infected pancreatic necrosis & 35 & 76.1 \\
\hline WOPN & 08 & 17.4 \\
\hline SAP with encephalopathy & 03 & 6.5 \\
\hline \multicolumn{3}{|l|}{ Modified CTSI } \\
\hline 10 & 28 & 60.9 \\
\hline 08 & 09 & 19.6 \\
\hline 06 & 05 & 10.9 \\
\hline 04 & 04 & 8.7 \\
\hline Pre-op Multiorgan failure & 21 & 45.6 \\
\hline Patients in ICU before surgery & 25 & 54.3 \\
\hline \multicolumn{3}{|l|}{ Pre-op drainage procedure } \\
\hline PCD & 12 & 26.1 \\
\hline Endoscopic & 03 & 6.5 \\
\hline No drainage & 31 & 67.4 \\
\hline \multicolumn{3}{|c|}{$\begin{array}{l}\text { [Table/Fig-2]: Demographics and clinical characteristics of } 46 \text { patients who } \\
\text { underwent Pancreatic Necrosectomy (PN). } \\
\text { WOPN: Walled-off pancreatic necrosis; SAP: Severe Acute Pancreatitis; CTSI: CT severity index } \\
\text { PCD: Percutaneous drainage }\end{array}$} \\
\hline
\end{tabular}

Escherichia coli was the most common single organism which was isolated in 16 cases (35\%), polymicrobial bacterial flora in 13 patients (28.3\%). In about five patients (11\%), culture was negative. Fungi were grown in three patients $(6.5 \%)$ wherein Candida haemolunii was the most common isolate, followed by Aspergillus. All patients with fungal culture positive among the fungus died, suggesting high mortality with fungal infection.

The outcomes in different surgical groups are shown in [Table/Fig-3]. Median postoperative ICU stay was 12 days with the range of 01-32 days. Additional procedures were required in 19 patients (41\%). Overall SSI rate was $61 \%$, VARD group has highest rate of about $85.7 \%$ followed by open group (80\%) and laparoscopic group (23.5\%).

\begin{tabular}{|l|c|c|c|c|}
\hline Parameter & $\begin{array}{c}\text { Laparoscopic } \\
\text { (LAP) group } \\
\text { (17) n (\%) }\end{array}$ & $\begin{array}{c}\text { VARD } \\
\text { group } \\
(14) \mathrm{n}(\%)\end{array}$ & $\begin{array}{c}\text { Laparotomy } \\
\text { (Open) group } \\
\text { (15) } \mathrm{n}(\%)\end{array}$ & $\begin{array}{c}\text { MIPN (LAP+VARD) } \\
\text { group (17+14=31) } \\
\mathrm{n}(\%)\end{array}$ \\
\hline $\begin{array}{l}\text { Median Post-op } \\
\text { ICU stay (days } \\
\text { (range)) }\end{array}$ & $10.5(2-26)$ & $6(01-32)$ & $14(01-29)$ & $10(01-32)$ \\
\hline Organ failure & $6(35.3)$ & $6(43)$ & $9(60)$ & $12(39)$ \\
\hline $\begin{array}{l}\text { Median Hospital } \\
\text { stay (days)/ } \\
\text { (range)) }\end{array}$ & $24(6-68)$ & $\begin{array}{c}37.5(10- \\
82)\end{array}$ & $36(6-98)$ & $33(6-82)$ \\
\hline Mortality & $2(12)$ & $5(36)$ & $5(33)$ & $7(23)$ \\
\hline $\begin{array}{l}\text { Additional } \\
\text { procedures }\end{array}$ & $5(29)$ & $8(57)$ & $6(40)$ & $13(42)$ \\
\hline SSI & $4(23)$ & $12(86)$ & $12(80)$ & $16(52)$ \\
\hline Haemorrhage & $2(12)$ & $4(29)$ & $1(7)$ & $6(19)$ \\
\hline Fistula & $4(24)$ & $4(29)$ & $4(27)$ & $8(27)$ \\
\hline Re-admissions & $4(24)$ & $2(14)$ & $1(7)$ & $6(19)$ \\
\hline $\begin{array}{l}\text { Recurrent } \\
\text { pancreatitis }\end{array}$ & $1(6)$ & $3(21)$ & $1(7)$ & $4(13)$ \\
\hline Incisional hernia & $1(6)$ & $0(0)$ & $1(7)$ & $1(3)$ \\
\hline [Table/Fig-3]: Outcomes in different surgical groups. & \\
\hline
\end{tabular}


Overall median hospital stay was 33 days with the range of 6-98 days. The overall mortality rate in patients who underwent necrosectomy was $26 \%$. The mortality between different groups is compared in [Table/Fig-4-6].

\begin{tabular}{|l|c|c|c|}
\hline Parameter & $\begin{array}{c}\text { Laparotomy } \\
\text { group (15) }\end{array}$ & $\begin{array}{c}\text { MIPN (LAP+VARD) } \\
\text { Group (31) }\end{array}$ & p-value* \\
\hline Mean post-op ICU stay & $14.18 \pm 9.86$ & $14.23 \pm 11.69$ & 0.991 \\
\hline Organ failure rate & $9(60 \%)$ & $12(39 \%)$ & 0.205 \\
\hline Mean hospital stay & $39.33 \pm 27.54$ & $31.45 \pm 19.40$ & 0.267 \\
\hline Mortality & $5(33 \%)$ & $7(23 \%)$ & 0.436 \\
\hline Additional procedures & $6(40 \%)$ & $13(42 \%)$ & 0.901 \\
\hline SSI & $12(80 \%)$ & $16(52 \%)$ & 0.064 \\
\hline Haemorrhage & $1(7 \%)$ & $6(19 \%)$ & 0.261 \\
\hline Fistula & $4(27 \%)$ & $8(27 \%)$ & 0.950 \\
\hline Re-admissions & $1(7 \%)$ & $6(19 \%)$ & 0.261 \\
\hline Recurrent pancreatitis & $1(7 \%)$ & $4(13 \%)$ & 0.524 \\
\hline Incisional hernia & $1(7 \%)$ & $1(3 \%)$ & 0.534 \\
\hline
\end{tabular}

[Table/Fig-4]: Outcomes in Open and MIPN groups.

MIPN: Minimal invasive pancreatic necrosectomy; VARD: Video-assisted retroperitoneal debridement; SSI: Surgical site infection; Mann-whitney test were used to find the significance difference between the length of stay and ICU stay with the groups; Chi-square test has been used to measure the association between the postoperative organ failure, mortality, additional procedures, SSI, haemorrhage, fistula re-admissions, recurrent pancreatitis and incisional hernia with groups

\begin{tabular}{|l|c|c|c|}
\hline Parameter & $\begin{array}{c}\text { Laparoscopic (LAP) } \\
\text { group (17) }\end{array}$ & $\begin{array}{c}\text { Laparotomy } \\
\text { group (15) }\end{array}$ & p-value* \\
\hline Mean post-op ICU stay & $13.83 \pm 9.57$ & $14.18 \pm 9.86$ & 0.944 \\
\hline Organ failure rate & $6(35.3 \%)$ & $9(60 \%)$ & 0.108 \\
\hline Mean hospital stay & $26.06 \pm 19.01$ & $39.33 \pm 27.54$ & 0.119 \\
\hline Mortality & $2(12 \%)$ & $5(33 \%)$ & 0.141 \\
\hline Additional procedures & $5(29 \%)$ & $6(40 \%)$ & 0.529 \\
\hline SSI & $4(23 \%)$ & $12(80 \%)$ & 0.001 \\
\hline Haemorrhage & $2(12 \%)$ & $1(7 \%)$ & 0.621 \\
\hline Fistula & $4(24 \%)$ & $4(27 \%)$ & 0.838 \\
\hline Re-admissions & $4(24 \%)$ & $1(7 \%)$ & 0.190 \\
\hline Recurrent pancreatitis & $1(6 \%)$ & $1(7 \%)$ & 0.927 \\
\hline Incisional hernia & $1(6 \%)$ & $1(7 \%)$ & 0.927 \\
\hline
\end{tabular}

[Table/Fig-5]: Outcomes in laparoscopic and open groups.

Mann-Whitney test were used to find the significance difference between the length of stay and ICU stay with the groups; Chi-square test has been used to measure the association between the postoperative organ failure, mortallty, additional procedures, SSI, haemorrhage, fistula, readmissions, recurrent pancreatitis and incisional hernia with groups

\begin{tabular}{|l|c|c|c|}
\hline Parameter & $\begin{array}{c}\text { Laparotomy group } \\
(\mathbf{1 5})\end{array}$ & $\begin{array}{c}\text { VARD group } \\
(\mathbf{1 4 )}\end{array}$ & p-value $^{*}$ \\
\hline Mean post-op ICU stay & $14.18 \pm 9.86$ & $14.57 \pm 14.02$ & 0.945 \\
\hline Post-op organ failure rate & $9(60 \%)$ & $7(50 \%)$ & 0.588 \\
\hline Mean hospital stay & $39.33 \pm 27.54$ & $38.0 \pm 18.44$ & 0.880 \\
\hline Mortality & $5(33 \%)$ & $5(36 \%)$ & 0.893 \\
\hline Additional procedures & $6(40 \%)$ & $8(57 \%)$ & 0.356 \\
\hline SSI & $12(80 \%)$ & $12(86 \%)$ & 0.684 \\
\hline Haemorrhage & $1(7 \%)$ & $4(29 \%)$ & 0.119 \\
\hline Fistula & $4(27 \%)$ & $4(29 \%)$ & 0.909 \\
\hline Re-admissions & $1(7 \%)$ & $2(14 \%)$ & 0.501 \\
\hline Recurrent pancreatitis & $1(7 \%)$ & $3(21 \%)$ & 0.249 \\
\hline Incisional hernia & $1(7 \%)$ & 0 & 0.210 \\
\hline
\end{tabular}

\section{[Table/Fig-6]: Outcomes in Open and VARD groups.}

Mann-Whitney test were used to find the significant difference between the length of stay and ICU stay with the groups; Chi-square test has been used to measure the association between the postoperative organ failure, mortality, additional procedures, SSI, haemorrhage, fistula, readmissions, recurrent pancreatitis and incisional hernia with groups

The long-term complications during the follow-up period till March 2016 were, occurrence of secondary diabetes mellitus in 18 (40\%) and exocrine insufficiency in 8 (18\%). The other complications were recurrent pancreatitis in 7 (15\%), biliary stricture $3(6 \%)$ and incisional hernia in $3(6 \%)$ in present study.

\section{DISCUSSION}

The NP remains a complex and challenging disease, even though several major improvements have occurred in the management of disease during the last three decades.

The incidence of postoperative organ failure varies between $8 \%$ to $50 \%$ in different series but many patients had pre-existing organ failure complicating the issue [12-16]. In the PANTER trial, the postoperative organ failure rate was $27 \%$ and $28 \%$ of patients had new ICU admission with median ICU stay of 10 days (range 0-281 days) [10]. In present study, $46 \%$ of the patients had postoperative organ failure and median postoperative ICU stay was 12 days (range 01-32 days).

Forty one percent of patients in present study required additional procedures after index necrosectomy and number of additional procedures required were in the range of 1-5 times/per patient. In the Dutch trial, numbers of operations required were in the range of 0-7 per patient [10].

Bleeding after necrosectomy is potentially life threatening. Retroperitoneal bleeding occurred in 7 (15.2\%) patients. In these, four patients (29\%) who underwent VARD had retroperitoneal bleed, among these re-explorative VARD was performed in three patients and one patient underwent laparotomy for control of bleed. One patient in open group had intra-abdominal bleed, which was managed by GDA angioembolisation followed by re-explorative laparotomy. Two patients in laparoscopic group had pancreatic bed bleeding, GDA angioembolisation was performed on one patient, subsequently underwent laparotomy in view of recurrent bleed. Laparotomy was performed on other patient to control the bleed.

Some studies suggest that bleeding is usually venous, not arterial, and that these patients have an increased mortality rate [17]. The incidence of haemorrhage ranges from 1-23\% [12,13,1719]. Present study with a mixture of open and minimal invasive necrosectomy, had a $15 \%$ of retroperitoneal bleeding. In a study from Mayo Clinic, $18 \%$ of the patients had postoperative bleeding. Although no direct mortality was attributed to haemorrhage, multivariate analysis postoperative haemorrhage was shown to be an independent prognostic factor [16].

The incidence of gastrointestinal fistula after necrosectomy in the study is $26 \%$. Of the seven patients with external fistula, three patients had spontaneous closure, two patients underwent successful pancreatic duct stenting, two patients had failed attempt of ERCP, of which one patient had spontaneous closure after six months and other patient had disconnected duct syndrome which was later managed by pancreaticogastrostomy. Of the four patients who developed colonic fistula, two patients underwent ileostomy, one patient had spontaneous closure and another patient died of sepsis with multiorgan failure, one patient had duodenal fistula for which feeding jejunostomy was done.

In the PANTER trial, $51 \%$ of patients had gastrointestinal fistula including both enterocutaneous and pancreatic fistula [10]. The incidences of $\mathrm{Gl}$ fistula reported were in the range of $1-43 \%$ $[12,15,17-24]$.

In a nationwide study from USA, the median length of hospital stay in pancreatic debridement group was 46 days [25].The median length of hospital stay in PANTER trial [10] was 50 and 60 days in MIPN and open group with the range of 1-287 days [10]. In a study from UK, the median total hospital stay was of 93 days (range 8-300 days) [26]. In present study, the median hospital stay among the patient who underwent necrosectomy is 33 days with the range of 6-98 days, and the median hospital stay among MIPN and open group were 33 days (6-82 days) and 36 days (6-98 days), respectively. 
The mortality varies between 4-27\% [27-29]. The overall mortality in Dutch trial was $17 \%$, and mortality in MIPN group Vs Open group was $19 \%$ and $16 \%$, respectively with no statistical significance was seen ( $p$-value-0.7) [10]. In present study, the overall mortality was $26 \%$, and mortality in MIPN vs open necrosectomy was $23 \%$ and $33 \%$, respectively. Though the mortality rate of $12 \%$ in laparoscopic group has not reached statistical significance $(P=0.14)$, it is observed that adoption of laproscopic approach will reduce the incidence of mortality rate.

The incidence of late complications after PN ranges to 50\% to $62 \%$ $[17,26,30,31]$. In present study, the incidence of late complications was $74 \%$ during follow-up, and $25 \%$ of these required surgical or endoscopic intervention. The incidence of late complications in PANTER trial [10] was exocrine insufficiency in $21 \%$, new onset diabetes mellitus in $27 \%$ of patients [10]. Similarly, in other series, $28-36 \%$ of patients developed endocrine insufficiency and $4-25 \%$ of patients developed exocrine insufficiency $[17,26,30,31]$. In present study, $40 \%$ of patients developed secondary diabetes mellitus and $18 \%$ of patients developed exocrine insufficiency. Interestingly, a recent study shows similar incidence of endocrine (32\%) and exocrine (18\%) insufficiency at a follow-up of 4.3 years [32]. Most patients regained their working capacity and preserved their marital status in their study.

In a study from UK, the incidence of biliary stricture after PN was 16. In this study, $6 \%$ of patients developed biliary stricture [26]. The incidence of incisional hernia was 16\% in PANTER trial and $2 \%$ in a study from UK $[10,26]$. In present series, $6 \%$ of patients developed incisional hernia.

Although, the reduction in mortality, new onset MOF, median ICU admission rate has not reached statistical significance, with the adoption of minimal invasive techniques there is a trend of lowering many of the short-term and delayed complications and thereby reducing the median hospital stay. We have observed that most of complications and mortality in both open and VARD groups were almost comparable and has not reached statistical significance. More number of patients in each arm will give more meaningful comparisons. Hence, a further study is needed.

The VARD has advantage of smaller incision and avoids contamination of peritoneal cavity, but because of space constraints possibility of near complete debridement, achieving complete haemostasis would be difficult, with more chances of injury to bowel thereby increasing the need of additional procedures which might contribute to the poor outcome. Further studies with larger sample size/pooled data are required. There is also a need to look into quality of life issues post pancreatic necrosetomy.

\section{Limitation(s)}

This was a retrospective study and though the number of complications and mortality were apparently low in minimally invasive surgery group, it did not translate into statistical significance owing to low sample size. Twenty one patients already had preoperative organ failure and they were counted to have postoperative organ failure though many of them improved after surgery. Further the incidence of long-term complications was low to deduce any meaningful comparisons between the groups. However, this study will give us an overall picture of outcomes of patients with PN. The sample may be increased by conducting a multicentre study with pooled sample size.

\section{CONCLUSION(S)}

Mortality rate, new onset MOF, and median ICU admission rate were similar with adoption of minimal invasive techniques though there was a trend of overall reduced complication rate. A long-term and close follow-up is advised in these patients for the late complications to be identified and treated. Further studies with larger sample size are required for attaining statistical significance. There is also a need to look into quality of life issues post pancreatic necrosetomy.

\section{REFERENCES}

[1] Neoptolemos JP, Raraty M, Finch M, Sutton R. Acute pancreatitis: The substantial human and financial costs. Gut. 1998;42(6):886-89.

[2] Beger HG, Rau B, Mayer J, Pralle U. Natural course of acute pancreatitis. World J Surg. 1997;21(2):130-35.

[3] Larvin M. Management of infected pancreatic necrosis. Curr Gastroenterol. 2008;10(2):107-14.

[4] Bradley EL. A clinically based classification system for acute pancreatitis. Summary of the international symposium on acute pancreatitis. Arch Surg.1993;128:586-90.

[5] Toouli J, Smith BM, Bassi C, Locke CD, Telford J, Freeny P, et al. Guidelines for the management of acute pancreatitis. J Gastroenterol Hepatol. 2002;17(1):15-39.

[6] Uhl W, Warshaw A, Imrie C, Bassi C, McKay CJ, Lankisch PG, et al. IAP Guidelines for the surgical management of acute pancreatitis.Pancreatology. 2002;2:565-73.

[7] Mier J, Leon LE, Castillo A, Robledo F, Blanco R. Early versus late necrosectomy in severe necrotising pancreatitis. Am J Surg. 1997;173:71-75.

[8] Beger $H G$, Büchler M, Bittner R, Block S, Nevalainen T, Roscher R. Necrosectomy and postoperative local lavage in necrotising pancreatitis. $\mathrm{Br} \mathrm{J}$ Surg.1988;75(3):207-12.

[9] Werner J, Hartwig W, Hackert T, Büchler MW. Surgery in the treatment of acute pancreatitis-open pancreatic necrosectomy. Scand J Surg. 2005;94(2):130-34.

[10] Van Santvoort HC, Besselink MG, Bakker OJ, Hofker SH, Boermeester MA, Dejong $\mathrm{CH}$, et al. A step-up approach or open necrosectomy for necrotising pancreatitis. NEJM. 2010;362(16):1491-502.

[11] Besselink MG, Van Santvoort HC, Nieuwenhuijs VB, Boermeester MA, Bollen TL, Buskens E,et al. Minimally invasive 'step-up approach' versus maximal necrosectomy in patients with acute necrotising pancreatitis (PANTER trial): Design and rationale of a randomised controlled multicenter trial [ISRCTN13975868]. BMC Surgery. 2006;6:6.

[12] Beattie GC, Mason J, Swan D, Madhavan KK, Siriwardena AK. Outcome of necrosectomy in acute pancreatitis: the case for continued vigilance. Scand $J$ Gastroenterol. 2002;37(12):1449-53.

[13] Beger HG, Büchler M, Bittner R, OettingerW, BlockS, Nevalainen T. Necrosectomy and postoperative local lavage in patients with necrotising pancreatitis: Results of a prospective clinical trial. World J Surg. 1988;12(2):255-62.

[14] Branum G, Galloway J, Hirchowitz W, Fendley M, Hunter J. Pancreatic necrosis: Results of necrosectomy, packing, and ultimate closure over drains. Ann Surg. 1998;227(6):870-77

[15] Connor S, Ghaneh P, Raraty M, Sutton R, Rosso E, Garvey C, et al. Minimally invasive retroperitoneal pancreatic necrosectomy. Dig Surg. 2003;20:270-77.

[16] Castellanos G, Piñero A, Doig LA, Serrano A, Fuster M, Bixquert V. Management of infected pancreatic necrosis using retroperitoneal necrosectomy with flexible endoscope: 10 years of experience. Surg Endosc. 2013;27(2):443-53.

[17] Tsiotos G, Luque-de Leon E, Soreide J, Bannon M, Zietlow S, Baerga-Varela Y, et al. Management of necrotising pancreatitis by repeated operative necrosectomy using a zipper technique. Am J Surg. 1998;175:91-98.

[18] Gotzinger P, Sautner T, Kriwanek S, Beckerhinn P, Barlan M, Armbruster C, et al. Surgical treatment for severe acute pancreatitis: Extent and surgical control of necrosis determine outcome. World J Surg. 2002;26(4):474-78.

[19] Bradley E III. A fifteen year experience with open drainage for pancreatic necrosis. Surg Gynecol Obstet. 1993;177:215-22.

[20] Carter R, McKay C, Imrie C. Percutaneous necrosectomy and sinus tract endoscopy in management of infected pancreatic necrosis: An initial experience. Ann Surg. 2001;232:175-80.

[21] Fernandez-del Castillo C, Rattner D, Makary M, Mostafavi A, McGrath D, Warshaw A. Debridement and closed packing for the treatment of necrotising pancreatitis. Ann Surg. 1998;228:676-84.

[22] Fugger R, Schulz F, Rogy M, Herbst F, Mirza D, Fritsch A. Open approach in pancreatic and infected pancreatic necrosis: Laparostomies and preplanned revisions. World J Surg. 1991;15:516-20.

[23] Castellanos G, Pinero A, Serrano A, Parrilla P. Infected pancreatic necrosis: Translumbar approach and management with retroperitoneoscopy. Arch Surg. 2002;137(9):1060-63.

[24] Beger H, Isenmann R. Surgical management of necrotising pancreatitis. Surg Clin North Am. 1999;79:783-800.

[25] Wormer BA, Swan RZ, Williams KB, Bradley JF $3^{\text {rd }}$, Walters AL, Augenstein $V A$, et al. Outcomes of pancreatic debridement in acute pancreatitis: analysis of the nationwide inpatient sample from 1998 to 2010. Am J Surg. 2014;208(3):350-62.

[26] Connor S, Alexakis N, Raraty MG, Ghaneh P, Evans J, Hughes M, et al. Early and late complications after pancreatic necrosectomy. Surgery. 2005;137(5):499-505.

[27] Parikh PY, Pitt HA, Kilbane M, Howard TJ, Nakeeb A, Schmidt CM, et al. Pancreatic necrosectomy: North American mortality is much lower than expected. J Am Coll Surg. 2009;209(6):712-19.

[28] Howard TJ, Patel JB, Zyromski N, Sandrasegaran K, Yu J, Nakeeb A, et al. Declining morbidity and mortality rates in the surgical management of pancreatic necrosis. J Gastrointest Surg. 2007;11(1):43-49.

[29] Van Santvoort HC, Bakker OJ, Bollen TL, Besselink MG, Ahmed Ali U, Schrijver AM, et al. Dutch Pancreatitis Study Group. A conservative and minimally invasive approach to necrotising pancreatitis improves outcome. Gastroenterology. 2011;141(4):1254-63. 
[30] Kriwanek S, Armbruster C, Dittrich K, Beckerhinn P, Redl E, Balogh B. Longterm outcome of surgical therapy of acute necrotising pancreatitis. Chirurg. 1996;67:244-48.

[31] Tzovaras G, Parks R, Diamond T, Rowlands B. Early and long-term results of surgery for severe necrotising pancreatitis. Dig Surg. 2004:21:41-46.
[32] Bartholdy A, Werge M, Novovic S, Hadi A, Nøjgaard C, Borch A, et al. Endoscopic treatment with transmural drainage and necrosectomy for walled-off necrosis provides favourable long-term outcomes on pancreatic function. United European Gastroenterol J. 2020;8(5):552-58.

\section{PARTICULARS OF CONTRIBUTORS:}

1. Assistant Professor, Department of Surgical Gastroenterology, KLES Dr. Prabhakar Kore Hospital and MRC, Belgaum, Karnataka, India

2. Assistant Professor, Department of Surgical Gastroenterology, Malabar Medical College Hospital, Kozhikode, Kerala, India.

3. Senior Consultant, Department of Surgical Gastroenterology, Manipal Hospitals, Bengaluru, Karnataka, India.

\section{NAME, ADDRESS, E-MAIL ID OF THE CORRESPONDING AUTHOR:}

Dr. R Santhosh,

Assistant Professor, Department of Surgical Gastroenterology and HPB Surgery,

Division of Gastro Sciences, Malabar Medical College, Modakkallur, Atholi Post,

Kozhikode, Kerala, India.

E-mail: drsanthoshr@ymail.com

\section{AUTHOR DECLARATION:}

- Financial or Other Competing Interests: None

- Was Ethics Committee Approval obtained for this study? Yes

- Was informed consent obtained from the subjects involved in the study? NA

- For any images presented appropriate consent has been obtained from the subjects. NA
PLAGIARISM CHECKING METHODS: Jain Het al.)

- Plagiarism X-checker: Jan 12, 2021

- Manual Googling: Mar 12, 2021

- iThenticate Software: Apr 12, 2021 (15\%)
ETYMOLOGY: Author Origin

Submission: Jan 01, 2021

Date of Peer Review: Feb 15, 2021

Date of Acceptance: Apr 05, 2021

Date of Publishing: Jul 01, 2021 